\title{
Complex interplay between tumor microenvironment and cancer therapy
}

\author{
Minhong Shen, Yibin Kang (西) \\ Department of Molecular Biology, Princeton University, Princeton, NJ 08544, USA \\ (C) The Author(s) 2018. This article is published with open access at link.springer.com and journal.hep.com.cn
}

\begin{abstract}
Tumor microenvironment (TME) is comprised of cellular and non-cellular components that exist within and around the tumor mass. The TME is highly dynamic and its importance in different stages of cancer progression has been well recognized. A growing body of evidence suggests that TME also plays pivotal roles in cancer treatment responses. TME is significantly remodeled upon cancer therapies, and such change either enhances the responses or induces drug resistance. Given the importance of TME in tumor progression and therapy resistance, strategies that remodel TME to improve therapeutic responses are under developing. In this review, we provide an overview of the essential components in TME and the remodeling of TME in response to anti-cancer treatments. We also summarize the strategies that aim to enhance therapeutic efficacy by modulating TME.
\end{abstract}

Keywords tumor microenvironment; therapy response; treatment resistance

\section{Introduction}

Cancer progression is a very complicated process, involving both malignant cells and surrounding components. Although accumulation of genetic and epigenetic alterations initiates cancer, tumor microenvironment (TME) is a key regulator of cancer progression. Immune effector cells that infiltrate and accumulate at TME keep the malignant cells under surveillance. TME also forms "barriers" to restrain cancer cell invasion and metastasis. On the other hand, TME can be subverted by cancer cells to facilitate the malignant progression of cancer. For example, TME may develop a number of biochemical and biophysical characteristics that are conducive to tumor progression, such as high interstitial fluid pressure, hypoxia, acidosis, and increased extracellular matrix (ECM) stiffness [1-4]. Moreover, TME negatively regulate immune effector cells by recruiting myeloid derived suppressor cells (MDSCs), tumor associated macrophages (TAMs), and regulatory $\mathrm{T}$ cells (Tregs) to provide an immunosuppressive niche for cancer [5].

The crucial role of TME in cancer therapeutic responses has also been recognized. Given the profound crosstalk that exists between malignant cells and TME, therapies

Received March 1, 2018; accepted July 5, 2018

Correspondence: Yibin Kang, ykang@princeton.edu that aim to eliminate cancer cells often stimulate the remodeling of TME. Studies suggest that chemo- and radiotherapies could modulate TME to be more immunogenic and result in a synergistic tumor killing effect [6-8]. In contrast, during treatments, TME could protect tumor cells by creating "barriers" to prevent drug penetration or immune effector cell infiltration $[9,10]$. Furthermore, TME could also be remodeled to mediate drug resistance by activating survival pathways in malignant cells upon treatments [11]. With growing knowledge of TMEmediated therapy resistance and the developing of nanotechnologies, approaches that increase therapeutic efficacy by remodeling TME are under developing. For instance, immune related therapies that aim to create a more immunogenic TME to enhance immune responses, and nanoparticles that modulate TME to increase the drug delivery efficiency have been successfully employed for cancer therapy $[11,12]$.

In this review we summarize the major components of TME and their roles in tumor progression. We then discuss the treatment-induced remodeling of TME and the strategies that were applied to modulate TME to improve cancer therapy.

\section{Microenvironment and tumor progression}

Tumors are composed of not only malignant cells but also 
many other non-transformed cells and secreted extracellular components. The crosstalk between malignant and non-transformed cells constitute the signaling milieu in the tumor microenvironment (TME), which is critical for tumor progression [13]. Non-transformed cells in TME include immune-related cells, fibroblasts, neuronal cells, endothelial cells and many other specialized stromal cells. Both the composition of TME and their functions are highly dynamic and diverse across different cancer types and disease stages. Here we highlight some of the key TME components and their positive or negative roles in tumor progression (Fig. 1). As stromal cells often play context-dependent, and sometimes even opposite roles in different cancer types, we do not intend to provide a comprehensive summary of their diverse role in major cancer types. Rather, the descriptions below provide examples to illustrate their important functions in cancer progression.

\section{Cellular components in the TME that suppress tumor progression}

Tumor-infiltrating lymphocytes (TILs) are often found in TME, and the levels of TILs are usually correlated with the prognosis of cancers [14]. Different types of lymphocytes

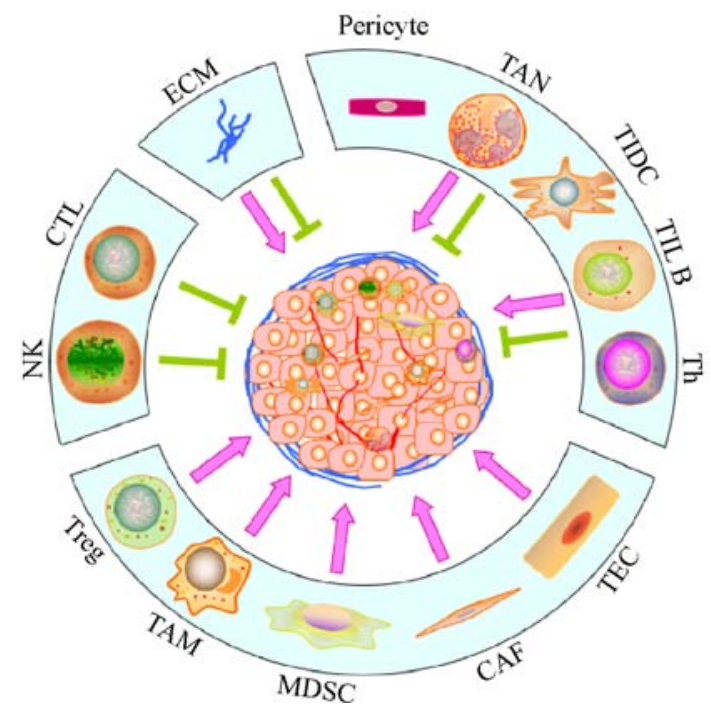

Fig. 1 TME components that regulate tumor progression. Schematic illustration of the major cellular and non-cellular components of TME that either promote (pink arrows) or inhibit (green "T" shapes) tumor progression. ECM, extracellular matrix; MDSC, myeloid derived suppressor cell; TAM, tumor-associated macrophage; Treg, regulatory $\mathrm{T}$ cell; CTL, cytotoxic T lymphocyte; NK, natural killer cell; CAF, cancer-associated fibroblast; TEC, tumor-associated endothelial cell; $\mathrm{Th}, \mathrm{CD}^{+}{ }^{+} \mathrm{T}$ helper lymphocyte; TIDC, tumor-infiltrating dendritic cell; TAN, tumorassociated neutrophil; TIL B, tumor-infiltrating lymphocyte B cell. have distinct functions in TME. $\mathrm{CD}^{+}$cytotoxic $\mathrm{T}$ lymphocytes (CTLs) are normally activated by antigens and capable of killing tumor cells. Their presence at TME is strongly associated with good prognosis [15]. A metaanalysis based on research literature in PubMed and Embase that contain CTLs status and patient survival data concluded that $\mathrm{CD} 8^{+}$CTLs is a good prognosis factor for survival, with a hazard ratio of 0.71 (95\% confidence interval (CI) $0.62-0.82$ ) [14].

Natural killer (NK) cells are another immune cell population that is capable of eliminating malignant cells and infected cells. Previous preclinical study indicated that in spontaneous leukemia and prostate cancer models, NK cells depletion accelerated tumor progression [16]. In line with this, the presence of NK cells in the TME correlated with clinical outcomes in a variety of cancers. In colorectal carcinomas, patients with little or moderate NK cells in TME had significantly worse overall and disease-free survival rates [17]. Likewise, in squamous cell lung cancer and several other cancer types, tumor-infiltrating NK cells were shown as a good prognostic factor [18-21]. Mechanistically, IL-2 has been demonstrated as a critical factor that mediate the activation of NK cells, leading to their tumor killing effects [22].

\section{Cellular components in TME that promote tumor progression}

Regulatory $\mathrm{T}$ cells (Tregs), which are characterized with Foxp3 and CD25 expression, are often associated with poor clinical outcomes [23]. Experimentally, removal of Tregs with anti-CD25 antibody in mouse models significantly increased CD8 ${ }^{+}$CTLs in TME and enhanced the rejection of tumors [24-26]. Mechanistically, Tregs exert an immune suppressive function through the production of IL-10, TGF- $\beta$ and cytotoxic T lymphocyte-associated antigen 4 (CTLA-4) [27].

Tumor-associated macrophages (TAMs), which are commonly identified by expression of CD163, CD204, or CD206, are prominent immune cells that orchestrate various stromal responses in TME $[28,29]$. The function of TAMs in promoting tumor progression has been well established. Previous studies indicated that the higher numbers of TAMs correlated with worse clinical outcomes in multiple cancer types. Specifically, the accumulation of CD163 ${ }^{+}$TAMs in malignant pleural effusion in lung cancer patients was closely correlated with poor prognosis [30]. CD204 ${ }^{+}$TAM was also reported as an independent poor prognostic factor in esophageal squamous cell carcinoma [31] and a high density of infiltrated TAMs is associated with aggressive features of gastric cancer as well [32]. Mechanistically, TAMs produce cytokines such as IL-6/IL-17/IL-23 or mitogens to induce the initiation and progression of cancer via the NF- $\mathrm{kB}$ or STAT3 signaling pathway in tumor cells [33-35]. 
Numerous reports describe the presence of myeloidderived suppressor cells (MDSCs) in both murine and human TME [36,37]. The main feature of MDSCs is their potent immune suppressive activity, which promotes tumor progression. MDSCs inhibit antigen-nonspecific, CD3/ CD28 mediated $\mathrm{T}$ cell proliferation, resulting in the suppression of immune responses in the TME [38]. Interestingly, elevated suppressive activity of tumor MDSCs was associated with a significant increase in the expression of genes associated with fatty acid oxidation [38], which provide an insight into the mechanisms underlying MDSCs-mediated immune suppression.

Cancer-associated fibroblasts (CAFs) are highly heterogeneous and originate from different cells, such as resident fibroblasts, epithelia cells, endothelia cells or mesenchymal cells [39]. It is one of the most crucial components of the TME in promoting tumor growth, invasion, and metastasis. Studies indicated that CAFs produce and secrete many growth factors and cytokines such as TGF$\beta$, hepatocyte growth factor (HGF), and fibroblast secreted protein-1 (FSP1) to support primary tumor growth [40,41]. CAFs can also promote angiogenesis by secreting stromal derived factor1 (SDF-1) to recruit endothelial cell precursors (EPCs) [41]. Interestingly, SDF-1 $\alpha$ (also known as CXCL12) binds to CXCR4 in tumors cells to directly stimulate cancer cell proliferation [42]. Moreover, CAFs may promote tumor growth through distinct pathways in different cancer types. For example, melanoma cells cannot produce insulin-like growth factor 1 (IGF-1) themselves to support tumor growth; instead, they rely on IGF-1 provided by surrounding CAFs [43]. In lung and prostate cancers, CAFs can respond to androgens to produce growth factors that induce epithelial proliferation $[43,44]$. In addition to secreting growth factors, CAFs can behave like a mutagen to increase the tumorigenic ability of cancer cells. For instance, CAFs generate reactive oxygen species (ROS) under low $\mathrm{pH}$ and hypoxia environment which act as a mutagen to the surrounding cells $[45,46]$. On the other hand, CAFs can also affect cancer cell growth by affecting their metabolic pathways [47]. It has been shown that chronic inflammation and cancer are closely related [48]. In mouse models of skin, breast and pancreatic tumors, CAFs express a proinflammatory gene signature, which contributes to the support of tumor growth by enhancing neovascularization and the recruitment of immune cells [42].

Other than promoting primary tumor growth, CAFs in TME also increase tumor invasion and metastasis. CAFs promote cancer invasion by secreting various matrixdegrading proteases as well as their activators such as uPA [49]. uPA can cleave matrix metalloproteinase (MMPs) to activate these proteins, and upregulation of MMPs activity results in significant extracellular matrix (ECM) degradation, which contribute to angiogenesis and metastasis [50].

Tumor endothelial cell (TEC) is another TME compo- nent that demonstrate distinct phenotypes from their normal counterparts. First, TECs usually have irregular shape and size [51]; second, TECs have distinct responsiveness to EGF, adrenomedullin and VEGF compared with normal endothelial cells [52-54]. Through a bidirectional interaction between tumor cells, TECs actively promote cancer metastasis [55]. Previous study also suggested that TECs isolated from highly metastatic tumors significantly enhanced the metastatic ability of weakly metastatic cancer cells in co-transplantation experiments [55]. Mechanistically, DNA demethylation in TECs causes upregulation and secretion of biglycan, which is a small leucine-rich repeat proteoglycan. Tumor cell migration is then activated by biglycan via NF- $\kappa \mathrm{B}$ and extracellular signal-regulated kinase 1/2 (ERK1/2) [55].

\section{Double-edged cellular components}

Previous study suggested that $\mathrm{CD} 8^{+} \mathrm{CTL}$ are regulated by $\mathrm{CD}^{+} \mathrm{T}$ helper lymphocytes $(\mathrm{Th})$, which are a class of heterogeneous cytokine secreting $\mathrm{T}$ lymphocytes in TME [15]. Th cells are critical for the immune response development against infection or malignancy [56]. In tumor context, Th can develop into Th1 and Th1 subtypes upon antigen activation, both of which are important for tumor progression. Th1 cells, which are characterized by the production of IL- 2 and IFN- $\gamma$, are associated with favorable clinical outcomes [15]. However, Th2 cells could have controversial effects on tumor progression [57].

Tumor-infiltrating lymphocyte B (TIL B) cells play critical roles in regulating tumor progression in cooperating with other resident cells in the TME. TIL B cells was previously reported as the second-best immune cell predictor (after $\mathrm{CD} 8^{+}$TILs) of positive disease outcome in metastatic melanoma [58]. The presence of B cells was also correlated with reduced relapse rate and increased survival in cervical cancer and lung cancer, respectively [59-61]. However, preclinical studies also indicated some tumor-promoting roles of B cells [62,63]. It is well characterized that TIL B cells can produce lymphotoxin, which is a survival factor that induce angiogenesis [64]. In prostate cancer models, the secreted lymphotoxin activates non-canonical and canonical NF- $\mathrm{kB}$ signaling and STAT3 in cancer cells, resulting in androgen-refractory growth and tumor progression [65-67]. Moreover, by upregulating IL8 , B cells can also promote bladder cancer metastasis through androgen receptor and MMP signaling pathways [68]. In summary, the TIL B cells play widely varied roles in tumor progression, and contribute to either tumor growth or antitumor immunity in different context.

Dendritic cells (DCs), which can uptake, process and present antigens, are characterized as one of the most potent antigen-presenting cells (APCs) [69]. They have been identified in the TME in many different cancer types with pivotal roles [70]. The tumor-infiltrating DCs 
(TIDCs) has been found to be correlated with good prognosis in some cancer types. For example, increased number of TIDCs infiltration in primary tumors has been shown to correlate with significantly longer patient survival and less incidence of metastatic disease in a variety of different cancer types [71]. However, due to the complexity of phenotype as well as the methods of identification, controversial results were shown in different studies. For instance, in colorectal carcinoma, patients with lower numbers of TIDCs have both better disease-free and overall survival [72].

Although the presence of neutrophils in tumors often associates with poor prognosis, the contribution of tumorassociated neutrophils (TANs) to disease progression is unclear. Many studies indicated that TANs play a protumor role in cancer progression. For instance, Bekes et al. showed that neutrophils produce MMP9 within the TME and contributes to angiogenesis, tumor progression, and metastasis in mouse transplantation models [73]. In contrast, other studies have suggested that TANs can play an anti-tumor role by activating the immune response against tumors and promoting tumor cell clearance [74]. Overall, the studies suggested that TANs display plasticity and can be polarized into either an anti-tumoral or protumoral phenotype depending on environmental factors.

Pericytes, also known as perivascular stromal cells, are an integral component of the tumor vasculature that provide structural support to blood vessels [75]. During tumor angiogenesis, the amount of pericytes that cover the vessels could vary dramatically. Clinical studies suggest that the pericyte coverage of tumor microvessels is correlated with cancer progression [76]. In melanoma and renal cell carcinoma, increased pericyte coverage is associated with aggressive clinicopathological features, resistance to therapy, and unfavorable clinical outcome of patients [77]. However, in bladder and colorectal cancers, low pericyte coverage of the vasculature correlates with poor prognosis and increased metastases [76,78]. Consistently, recent studies reported that pericyte ablation leads to increased vessel permeability and poor vessel integrity, which inhibited tumor growth but also promoted blood vessel invasion and metastatic spread $[79,80]$. These findings illustrate multi-faceted roles of pericytes in tumor progression.

\section{Non-cellular components}

Other than cytokines, chemokines, and growth factors that secreted by the cells discussed above, the major noncellular component of TME is the ECM. The ECM not only provides a physical scaffold for transformed and nontransformed cells but also directly regulates the homeostasis of TME and the progression of tumors. ECM is composed of a variety of proteins with distinct physical and biochemical properties, such as glycoproteins, pro- teoglycans, and polysaccharides [81]. All these proteins are deposited by both malignant and other cellular components in TME. During the progression of tumor, ECM changes dynamically in composition [82]. With a proteomics-based discovery approach, Naba et al. defined ECM signatures of poorly and highly metastatic mammary carcinomas [82]. It has been shown that in $\mathrm{ER}^{-} / \mathrm{PR}^{-}$breast cancer patients, higher expression of ECM proteins LTBP3 and SNED1 in TME is associated with worse prognosis [82]. On the other hand, ECM proteins that inhibit breast cancer progression and metastasis, and correlate with good prognosis in patients have also been identified, such as IGFBP4 and TINAGL1 $[82,83]$.

Taken together, different TME components have distinct functions in tumor progression (Fig. 1). Moreover, the function of each components could be context-dependent in different cancer types. Therefore, development of therapeutic approach targeting the TME needs to consider specific role of each TME component in a particular cancer type.

\section{Treatment-induced TME remodeling}

As mentioned above, TME has a variety of cellular and non-cellular components, which are dynamically changing during tumor progression. On the other hand, treatments aiming at inhibiting tumor progression also modulate the TME. The treatment-induced TME remodeling could either synergistically promote tumor cell elimination or cause therapy resistance and ultimately restore tumor progression (Fig. 2).

\section{Chemo- and radiotherapies}

Although chemo- and radiotherapies have substantial adverse effects on cancer patients, they are still widely applied in cancer treatments especially for those diseases that effective targeted therapy has not been developed, such as triple-negative breast cancer and pancreatic cancer [84]. However, most of the cancers develop resistance to chemo- and radiotherapies at late stages $[84,85]$. The mechanisms of the resistance are still largely unknown. A growing body of evidence suggests that chemo- and radiotherapies remodel TME, which in turn induces therapy resistance.

After chemotherapy, the damaged TME could undergo remodeling processes and become a tumor-promoting environment. Previous studies indicated that chemotherapy induces DNA damage-activated NF- $\mathrm{KB}$ pathway, which then upregulates the Wnt family member WNT16B. Increased WNT16B in TME activates the canonical Wnt signaling pathway in tumors and attenuates the effects of chemotherapy [86]. In mouse model studies, paclitaxel and doxorubicin treatments have been reported 


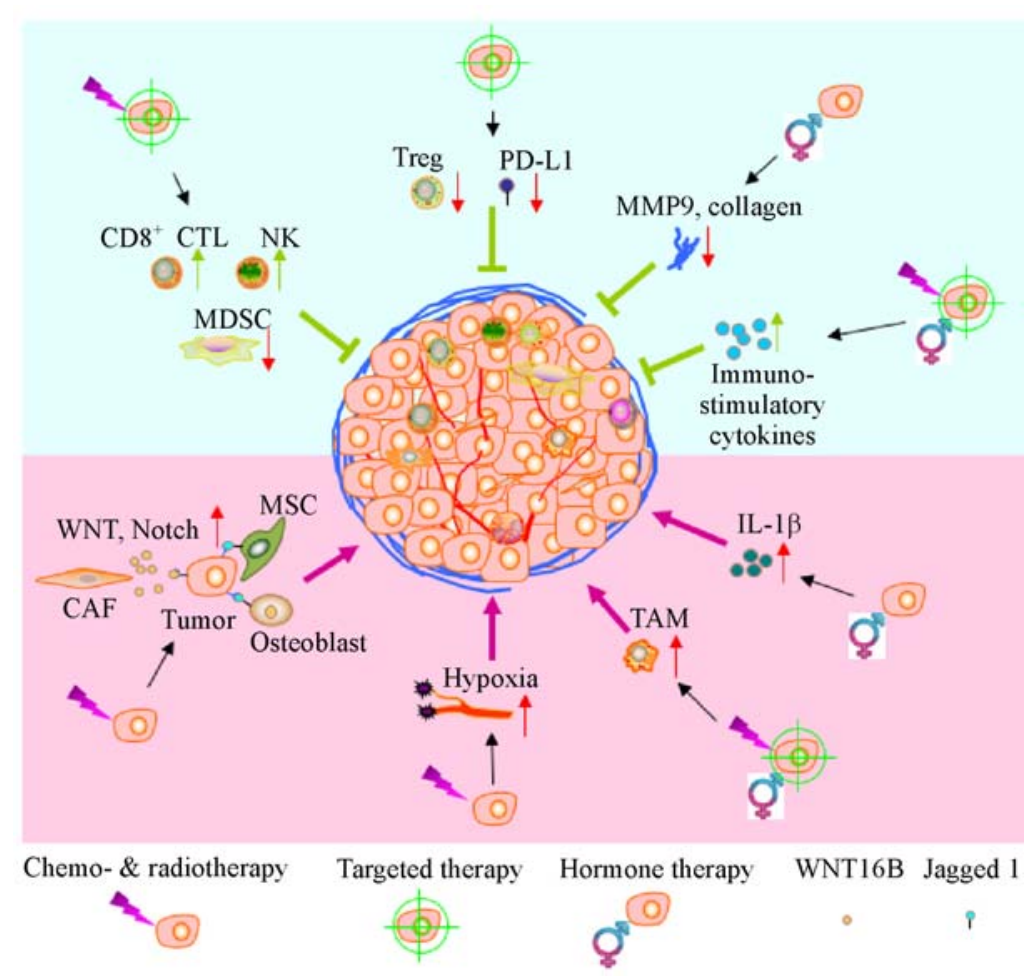

Fig. 2 Treatment-induced TME remodeling that inhibits tumor progression or promotes treatment resistance. Top: treatment-induced TME remodeling with tumor inhibitory effect: chemo-/radio- and some target therapies could increase CTL and NK cell infiltration or activities, and decrease MDSC number in TME; targeted therapy could downregulate Tregs and the expression of PD-L1 in TME; hormone therapy could modulate ECM by reducing MMP9 and collagen; and all three therapies could increase immunostimulatory cytokines in the TME. Bottom: TME remodeling-induced treatment resistance: chemo/radiotherapy could upregulate WNT and Notch signaling in tumor cells by increasing WNT16B secretion from CAF, or Jagged1 expression in MSC and osteoblasts; chemo/radiotherapy could also disrupt vessels to induce hypoxia; all three therapies could recruit more TAM into TME; and hormone therapy could increase expression of resistant-promoting cytokines, such as IL-1 $\beta$. MSC, mesenchymal stem cell.

to increase the recruitment of TAMs in PyMT-MMTV mammary carcinoma, which then induces the treatment resistance $[87,88]$. Similarly, gemcitabine treatment recruits more TAMs into TME with immune suppressive functions in mouse pancreatic cancer model [89]. It has also been shown recently that chemotherapy agents, such as paclitaxel and cisplatin, remodel TME by inducing Jagged 1 expression in osteoblasts and mesenchymal stem cells, which feeds back to tumor cells to activate Notch signaling and promotes chemo-resistance [90].

Similar to chemotherapy-induced treatment resistance, many aspects of the TME can render a tumor to become resistant to radiotherapy. Radiotherapy remodels TME by inducing endothelial cell dysfunction and damaging tumor vasculature, and therefore, resulting in hypoxia, which is a key regulatory factor in tumor growth $[91,92]$. The crucial role of hypoxia in radiotherapy resistance has been well characterized [92,93]. Similar to chemotherapy, radiotherapy also increases TAMs in TME, resulting in immunosuppression and tumor progression [94].

Therapy-induced TME alterations are not always tumor- promoting. In some cases, chemo- and radiotherapies could foster anti-tumor activity by changing the TME. Gemcitabine and 5-fluorouracil (5FU) treatments were selectively cytotoxic on MDSCs and the elimination of MDSCs increased the activity of $\mathrm{CD}^{+}$cells [6]. Treatment of eribulin mesylate, which is a tubulin binding drug, inhibits tumor progression by increasing the vessels density and NK cell infiltration in TME [8]. Similarly, tumor irradiation could induce damage responses that change the predominant TME cytokine profile toward an immunostimulatory profile, leading to the immunogenic cell death of cancer cells $[7,95]$.

\section{Targeted therapy}

Given that fact that more and more signaling pathways have been identified to be crucial for cancer progression and the key molecules in these pathways have been discovered, targeted therapies have been increasingly applied in cancer treatments. Many of the key molecule targets of such therapies are critical for TME assembling 
and remodeling. Changing of the TME could significantly affect the efficacy of treatments, which either promote tumor regression or induce resistance.

Sorafenib is a small molecule inhibitor of several tyrosine protein kinases, such as VEGFR, PDGFR, and Raf family kinases [96,97], and has been approved for advanced renal carcinoma, hepatocellular carcinoma (HCC), and radioactive iodine resistant advanced thyroid carcinoma. Preclinical study with HCC mouse model revealed that sorafenib treatment increased the activation of NK cells in TME, thereby promoting tumor regression [98]. Similarly, it has been shown that treatment with sunitinib, another multi-target receptor tyrosine kinase inhibitor, significantly decreased the number of MDSCs and Tregs, and increased CTLs in TME [99]. Suh et al. demonstrated that treatment of afatinib and lapatinib, which are EGFR and HER2 inhibitors, suppressed both the PD-L1 expression and expression of cytokines, such as CCL2, CCL21, and CXCL1, in the TME [100]. Moreover, studies suggested that PARP inhibitor BMN673 increased the proportion of cytotoxic immune cells while simultaneously decreasing the proportion of immunosuppressive cells in BRCA-deficient ovarian cancer mouse [101]. Based on the promising results, there are several ongoing trials combining PARP and immune checkpoint inhibitors [102].

In contrast to positive synergy shown in the examples above, target therapies have also been shown to modulate TME and resulted in a treatment resistant environment. For example, using the cis-Apc/Smad4 mouse model of locally invasive intestinal adenocarcinoma, Fujishita et al. found that mTOR inhibitors administration induced the activation of EGFR and MEK/ERK signaling in stromal cells, leading to treatment resistance [103]. In contrast to $B R C A$-deficient ovarian cancer model, olaparib and talazoparib, which are PARP inhibitors, upregulated PDL1 expression via GSK3 $\beta$ signaling and induced an immune suppressive TME in breast cancer models [104]. In addition, therapeutic mAb cetuximab that targeted EGFR increased the tumor-promoting TAMs in TME and attenuated treatment responses [105].

\section{Hormonal therapy}

Anti-estrogen hormone therapy is routinely applied as adjuvant treatment for breast cancer patients with estrogen receptor- $\alpha(E R \alpha)$ positive tumors. However, a high percentage of patients develop resistance, and up to one third of them have cancer recurrence within 15 years [106]. Previous studies suggest that hormone therapy could modulate TME which then induces treatment resistance. Specifically, it has been observed that cytokine profile in the TME was changed upon ER $\alpha$ suppression, for example, IL-1 $\beta$ level is significantly unregulated [107]. In presence of IL-1 $\beta$, tamoxifen acts as an agonist rather than an antagonist, and promotes tumor progression [108].
Androgen deprivation therapy (ADT) is an effective treatment for initial suppression of prostate cancer progression. However, many patients develop ADT resistance which leads to the development of incurable disease. A growing body of evidence suggests that macrophages in TME are critical in promoting ADT resistance. For example, large numbers of TAMs were recruited to the TME shortly after ADT [109-111]. Moreover, the TAMs recruitment is associated with an increase in cancer cell proliferation [111,112]. In contrast, abiraterone acetate (ABA), which is a steroidal CYP17A1 inhibitor and by extension androgen synthesis inhibitor, remodels TME to enhance treatment response. ABA administration blocks the deposition of collagen in TME in Pten-deficient prostate cancer model [113]. ABA treatment also alters cytokine and chemokine profiles, such as upregulating metalloproteinase 1 (mTIMP1), keratinocyte-derived chemokine ( $\mathrm{KC}$ or termed mCXCL1), chemokine (C-X-C motif) ligand-2 (mCXCL2), thymus and activation regulated chemokine (TARC or termed mCCL17), and downregulating interferon $\gamma$-induced protein IP-10 (also called mCXCL10), macrophage inflammatory protein- $1 \alpha$ (MIP- $1 \alpha$ or mCCL3), macrophage inflammatory protein- $1 \beta$ (MIP-1 $\beta$ or mCCL4), and transforming growth factor $\beta 1$ (mTGF$\beta 1)$ [113]. Furthermore, ABA treatment decreases MMP9 expression in the TME of Pten null tumors in mice, and inhibits tumor progression [113].

In conclusion, therapies that target cancer cells could change the TME composition profoundly, which in turn significantly affects the therapeutic efficacy (Fig. 2). Given the critical roles of TME in tumor progression, the remodeling of TME upon treatment should be taken into consideration during cancer therapy.

\section{Modulating TME to improve cancer therapy}

As discussed above, TME is not only involved in tumor progression but also plays pivotal roles in cancer treatment responses. Moreover, cancer treatments could modulate TME to form a therapy-resistant niche and promote tumor progression. Therefore, there is increasing interest in targeting or remodeling the TME as a strategy to optimize therapeutic effects (Fig. 3).

\section{Immune-related strategies}

The TME often limits infiltration of effector T cells into the tumors, and diminishes $\mathrm{T}$ cell expansion, or reduces the viability of CTLs [114]. Thus, TME provides an immune suppressive niche to help cancer cells escape from immune surveillance. To counter this, a variety of immunotherapies that remodel TME components have been developed and shown promising clinical outcomes. 


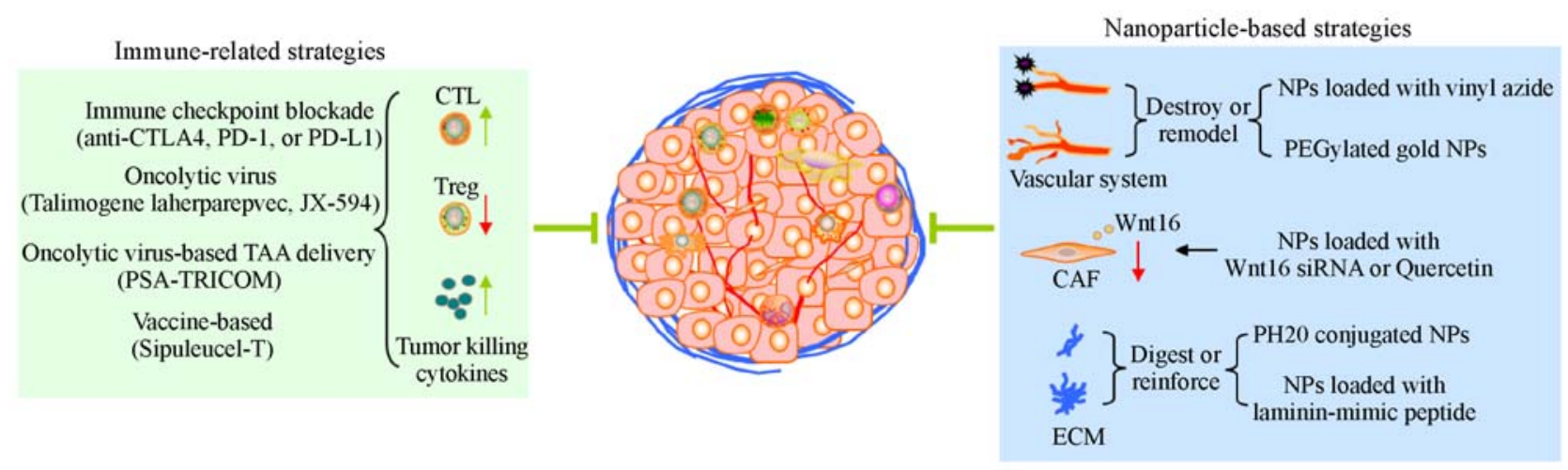

Fig. 3 Modulating TME to improve therapeutic responses. Immune-related strategies, such as immune checkpoint blockade, oncolytic virus, and oncolytic virus or vaccine based TAA delivery, could remodel TME by enhancing the activity of effector T cells, such as CTL, decreasing the activity of Tregs, and increasing tumor killing cytokines, such as INF- $\gamma$ and TNF- $\alpha$. Nanoparticles could modulate TME by disrupting or remodeling vessel growth to inhibit tumor growth or enhance drug delivery respectively. Nanoparticles could also target CAFs to decrease Wnt16 secretion. Moreover, nanoparticles conjugated with recombinant human hyaluronidase PH20 could digest ECM to improve drug delivery and reduce hypoxia. Other strategies such as nanoparticles loaded with laminin-mimic peptide could also mimic and reinforce ECM to prevent dissemination of tumor cells. TAA, tumor-associated antigen; NPs, nanoparticles.

Immune checkpoint blockade therapy, which employed antibodies that target CTLA-4 or the programmed cell death protein 1 pathway (PD-1/PD-L1), has demonstrated promising responses in many malignancies [115]. Given that costimulatory signals are critical for the $\mathrm{T}$ cell activation, the binding of B7-1 (CD80) or B7-2 (CD86) molecules on the antigen-presenting cells with CD28 molecules on the $\mathrm{T}$ cell provides such costimulatory signal to promote the proliferation and activation of T cells [116]. On the other hand, CTLA-4, which is a homolog of CD28 but with higher binding affinity, competes with $\mathrm{CD} 28$ to bind B7 [117,118]. CTLA-4/B7 binding generates inhibitory signals that suppress the stimulatory signals from CD28/B7 interaction [119]. Similarly, as a member of B7/ CD28 family of costimulatory receptors, PD-1 inhibits the production of IFN- $\gamma$, TNF- $\alpha$, and IL-2, reduces T cell proliferation and survival upon binding to its ligands (PDL1/2) [120]. In contrast to CTLA-4, which mainly functions to regulate the activation of $\mathrm{T}$ cells, PD-1 pathway induces immune suppression by regulating effector T cell activity. Specifically, PD-1 pathway induces $\mathrm{T}$ cell exhaustion, increases their apoptosis, decreases the proliferation of activated $\mathrm{T}$ cells, enhances the function of regulatory $\mathrm{T}$ cells, and restrains $\mathrm{T}$ cell activation and cytokine production [121].

Preclinical studies suggest that CTLA-4 pathway blockade decreases tumor growth and improves survival [122]. Monoclonal antibodies that block CTLA-4 have been approved for melanoma and lung cancer, and are under clinical trials for other cancer types [123]. The mechanism through which anti-CTLA-4 antibodies inhibit tumor progression is still elusive. However, previous study suggested that CTLA-4 blockade therapy induced activation of $\mathrm{CD}^{+}$and $\mathrm{CD}^{+}$effector cells in TME in solid tumors [124]. For example, melanoma patients treated with
anti-CTLA-4 monoclonal antibody have increased expression of HLA-DR, which is a marker of T cell activation, in both $\mathrm{CD}^{+}$and $\mathrm{CD} 8^{+}$cells [125]. Moreover, mouse model studies indicate that Tregs in CTLA-4 deficient mice have impaired immune suppressive functions [126,127]. Collectively, immune checkpoint blockade therapy with antiCTLA-4 antibodies increases the effector T cell population and impairs the immune suppressive functions of Tregs in TME to inhibit tumor progression.

Similar to the success of anti-CTLA-4 therapy, targeting PD-1 pathway in melanoma and non-small cell lung cancer (NSCLC) also showed dramatic therapeutic efficacy in patients [123]. Antibodies against PD-1 or PD-L1 are also under clinical trials in many other cancer types [128]. Consistent with observations made in preclinical models, PD-1 immune checkpoint blockade therapy profoundly remodels the TME in cancer patients. In one of the recent studies, the authors performed extensive immunogenomic analyses on melanoma samples treated with anti-PD-1 therapy. 68 patients with advanced melanoma, whose diseases progressed on anti-CTLA-4 therapy or were antiCTLA-4 therapy naïve were employed to characterize how tumor genomic and TME features changed over time after anti-PD-1 therapy [129]. The authors found that mutation and neoantigen load were reduced from baseline in TME among patients who were responding to the therapy [129]. Analysis of TME heterogeneity during therapy demonstrated differential clonal evolution within tumors and putative selection against neoantigenic mutations. Moreover, transcriptome analyses before and during anti-PD-1 therapy revealed that immune cell subsets, activation of specific transcriptional networks, and immune checkpoint genes were dramatically upregulated in TME of responders. Temporal changes in intratumoral $\mathrm{T}$ cell reporter repertoire also indicated the expansion of distinct $\mathrm{T}$ cell 
clones in the TME in the setting of neoantigen loss [129]. The study demonstrates a dramatic remodeling upon antiPD-1 therapy and provides insight into the mechanism of action.

Other than inhibiting immune inhibitory pathways to increase the activity of specific immune populations in TME, strategies that enhance the general immunogenic property of TME have also been employed, such as oncolytic viral therapy and vaccine based cancer therapies. Oncolytic viral therapy, which aims to use virus to infect cancer cells and destroy them by oncolysis, not only causes direct tumor cell destruction but also stimulates anti-tumor immune responses. Talimogene laherparepvec is the first oncolytic herpes virus that has been approved for the treatment of advanced inoperable melanoma. Previous studies demonstrated that oncolytic viruses can be modified to encode numerous immune enhancing cytokines, including IL-2, IL-12, and IFN- $\gamma[130]$. On the other hand, Mastrangelo et al. demonstrated that JX-594, which is an oncolytic virus expressing granulocyte macrophage colony-stimulating factor (GM-CSF), significantly increased the $\mathrm{CD}^{+}$and $\mathrm{CD}^{+} \mathrm{T}$ infiltration in a phase $\mathrm{I}$ clinical trial in patients with refractory melanoma [131133]. In line with the results, intratumoral injection of the oncolytic herpes simplex virus expressing GM-CSF in melanoma patients resulted in the generation of systemic tumor antigen-specific T-lymphocyte responses, as well as decreases in Tregs $[134,135]$.

In parallel, oncolytic viruses as vectors for expression of tumor-associated antigen (TAA) have also been employed. Preclinical studies indicated that intratumoral subcutaneous priming and intratumoral boosting was obtained with the delivery of recombinant vaccinia virus expressing TAA [136,137]. Several clinical trials are undergoing and support the advantages of intratumoral poxviruses expressing TAA $[138,139]$. In summary, the studies indicate that oncolytic viruses can be used as tools to modify the immunological components of the TME to improve the outcomes of cancer therapy.

The concept of vaccine-based cancer therapy is similar to oncolytic viral therapy. Vaccines are made up of cancer cells, parts of cells, or pure antigens to transform the TME to support an improved antigen presentation and generation of immune responses that are specific to immunogenic TAA. Sipuleucel-T, which is the first FDA approved vaccine for metastatic prostate cancer treatment, is a good example for this category. Sipuleucel-T was designed to stimulate immune response to prostatic acid phosphatase in patients, which in turn eliminate prostate cancer cells [140].

\section{Nanoparticle-based strategies}

Due to the fast developing of nanomedicine technology, strategies that utilize nanoparticles (NPs) to remodel TME in order to improve the treatment responses are also under development.

The abnormality of the vascular system is one of the major features of TME, which promotes tumor progression and is a major hurdle for effective drug delivery. It has been well demonstrated that abnormal tumor vessels often grow rapidly to meet the nutrient demand to maintain tumor progression [141]. In this regard, disrupting the abnormal vascular system in TME could deplete the nutrition supply and induce tumor regression. To this end, technologies that disrupt tumor vascular system with NPs have been developed. In a previous study, vinyl azide was loaded into RGD-modified hollow copper sulfide NPs to generate a near-IR (NIR) laser-activated "nanobomb." N2 bubbles were released from the vinyl azide on NIR irradiation due to the increased local temperature at the tumor sites. The bubbles were then exploded in the tumors, resulting in disruption of the neovasculature, leading to tumor regression [142]. However, this method could also disrupt normal vessels and has significant off-target toxicity. To achieve tumor-specific vascular disruption, PEGylated gold NPs modified with a tumor neovasculature-targeting ligand (RGD) have been developed. RGD-guided specific tumor vascular damage was observed and off-target toxicity was dramatically reduced [143]. In parallel, NPs that facilitates drug delivery in solid tumors by normalizing tumor vessels are also under developing. NPs that normalize vascular in TME could also change the hypoxia status, and therefore, inhibit abnormal angiogenesis and tumor growth [12].

CAFs represent one of the major tumor-promoting stromal components in TME. Several recent studies have aimed to design NPs to target CAFs [144-146]. Wnt16 secreted by CAFs has been reported to be critical for the treatment resistance [144]. To downregulate Wnt16, liposome-protamine-hyaluronic acid (LPH) NPs loaded with anti-Wnt16 siRNAs were delivered to TME in a bladder carcinoma model to inhibit tumor progression [144]. Quercetin, which is a dietary flavonoid, can also decrease the expression of Wnt16. Delivery of quercetin that is loaded on lipid-calcium-phosphate NPs to the TME also enhanced the therapeutic efficacy [145].

As mentioned above, the tumor ECM, which is composed of a number of secreted proteins, creates an integrated 3D macromolecular network to regulate tumor progression and metastasis. ECM could also behave like a barrier to prevent drug penetration. Specifically, animal model experiments showed that mice with ECM-rich A549 tumors have significant less Cy5.5-labled glycol chitosan NPs infiltration than ECM-less SCC7 tumors [147]. Treatment with hyaluronidase (HAase), which disrupts ECM, dramatically increased the penetration of Cy5.5labled glycol chitosan NPs in ECM-rich A549 tumors [147]. Inspired by the findings, recombinant human HAase PH20 was conjugated on the surface of poly (lactic-co- 
glycolic acid) (PLGA) NPs to modulate ECM. The study revealed that PH20 conjugated NPs treatment achieved significantly improved distribution of NPs in 4T1 breast cancer xenograft mice due to ECM degradation and increased interstitial diffusion in solid tumors [148]. Interestingly, delivery of the NPs could also increase tumor vessel density, thereby increasing drug delivery efficacy and enhancing therapeutic effects [149].

ECM serves as a barrier to prevent not only drug penetration but also tumor cell invasion and metastasis. To overcome the obstacles of the ECM, tumor cells need to overexpress certain proteolytic enzymes, such as MMPs [150]. Based on this observation, several groups are developing NPs to mimic and reinforce ECM in the TME to inhibit metastasis. For example, to prevent tumor invasion and metastasis, a transformable laminin-mimic peptide (BP-KLVFFKGGDGRYIGSR) was generated [151]. The BP motif of the peptide could self-assemble onto NPs due to the strong hydrophobic interactions. Because of the similarity with natural laminin, the peptides on the NPs could readily transform into nanofibers around the solid tumor upon binding to integrins and laminin receptors to form an artificial ECM [151]. The results indicated that the artificial ECM remained at the tumor site for a couple of days which significantly inhibited the lung metastasis in breast and melanoma tumor models [151]. The clinical utility of such therapeutic strategy remains to be tested in relevant clinical settings.

Therapy resistance is one of the most significant hurdles for curative cancer treatment. Given the critical importance of TME in tumor progression, immune-related and nanoparticle based strategies have been developed to modulate TME to minimize resistance and enhance therapeutic efficacy (Fig. 3). With further optimization, these new therapeutic strategies may eventually lead to significant reduction of cancer related death.

\section{Conclusions}

Cancer progression is a systematic progress that both malignant cells and surrounding microenvironment are involved. Malignant cells and TME have profound impacts on each other during tumor progression. It has been well recognized that cancer therapies do not just destroy malignant cells, but also change the TME which then contribute to the success or failure of the treatments. Chemo-, radio-, targeted-, and hormone therapies could modulate TME in positive or negative ways, leading to either enhanced anti-tumor activity or, in contrast, a more favorable environment for tumor growth. Due to the importance of TME in tumor progression and therapeutic resistance, strategies that remolding TME have been developed to improve cancer therapy. Although these strategies, most notably the immune checkpoint blockade therapy, have promising outcomes in some cancer types, there are still many patients who do not response to the treatment or develop resistance. Moreover, oncolytic virusand cancer vaccine-based therapies that aim to boost immune response in TME could also encounter de novo or acquired resistance.

Tumor and TME dynamically interact, communicate, and regulate each other during treatments, which makes it exceedingly difficult to achieve successful outcome with mono-therapy. A growing body of evidence indicates that applying multiple therapeutic approaches could complement each other to overcome the resistance. Given the accumulating knowledge on TME remodeling during tumor progression and treatment, the future looks promising for combining tumor-specific treatments with TME targeting agents to achieve effective control or cure of cancer.

\section{Compliance with ethics guidelines}

Minhong Shen and Yibin Kang declare no conflict of interest. This manuscript is a review article and does not involve a research protocol requiring approval by the relevant institutional review board or ethics committee.

Open Access This article is distributed under the terms of the Creative Commons Attribution 4.0 International License (http:// creativecommons.org/licenses/by/4.0/), which permits unrestricted use, distribution, and reproduction in any medium, provided the appropriate credit is given to the original author(s) and the source, and a link is provided to the Creative Commons license, which indicates if changes are made.

\section{References}

1. Fukumura D, Jain RK. Tumor microenvironment abnormalities: causes, consequences, and strategies to normalize. J Cell Biochem 2007; 101(4): 937-949

2. Justus CR, Dong L, Yang LV. Acidic tumor microenvironment and pH-sensing G protein-coupled receptors. Front Physiol 2013; 4: 354

3. Justus CR, Sanderlin EJ, Yang LV. Molecular connections between cancer cell metabolism and the tumor microenvironment. Int J Mol Sci $2015 ;$ 16(5): 11055-11086

4. Lin CS, Lee HT, Lee MH, Pan SC, Ke CY, Chiu AW, Wei YH. Role of mitochondrial DNA copy number alteration in human renal cell carcinoma. Int J Mol Sci 2016; 17(6): E814

5. Ruella M, Klichinsky M, Kenderian SS, Shestova O, Ziober A, Kraft DO, Feldman M, Wasik MA, June CH, Gill S. Overcoming the immunosuppressive tumor microenvironment of Hodgkin lymphoma using chimeric antigen receptor $\mathrm{T}$ cells. Cancer Discov 2017; 7(10): 1154-1167

6. Liu Q, Liao Q, Zhao Y. Chemotherapy and tumor microenvironment of pancreatic cancer. Cancer Cell Int 2017; 17(1): 68

7. Krysko DV, Garg AD, Kaczmarek A, Krysko O, Agostinis P, Vandenabeele P. Immunogenic cell death and DAMPs in cancer therapy. Nat Rev Cancer 2012; 12(12): 860-875 
8. Ito K, Hamamichi S, Abe T, Akagi T, Shirota H, Kawano S, Asano M, Asano O, Yokoi A, Matsui J, Umeda IO, Fujii H. Antitumor effects of eribulin depend on modulation of the tumor microenvironment by vascular remodeling in mouse models. Cancer Sci 2017; 108(11): 2273-2280

9. Grantab R, Sivananthan S, Tannock IF. The penetration of anticancer drugs through tumor tissue as a function of cellular adhesion and packing density of tumor cells. Cancer Res 2006; 66 (2): 1033-1039

10. Netti PA, Berk DA, Swartz MA, Grodzinsky AJ, Jain RK. Role of extracellular matrix assembly in interstitial transport in solid tumors. Cancer Res 2000; 60(9): 2497-2503

11. Wu T, Dai Y. Tumor microenvironment and therapeutic response. Cancer Lett 2017; 387: 61-68

12. Chen Q, Liu G, Liu S, Su H, Wang Y, Li J, Luo C. Remodeling the tumor microenvironment with emerging nanotherapeutics. Trends Pharmacol Sci 2018; 39(1): 59-74

13. Whiteside TL. The tumor microenvironment and its role in promoting tumor growth. Oncogene 2008; 27(45): 5904-5912

14. Gooden MJ, de Bock GH, Leffers N, Daemen T, Nijman HW. The prognostic influence of tumour-infiltrating lymphocytes in cancer: a systematic review with meta-analysis. Br J Cancer 2011; 105(1): 93-103

15. Fridman WH, Pagès F, Sautès-Fridman C, Galon J. The immune contexture in human tumours: impact on clinical outcome. Nat Rev Cancer 2012; 12(4): 298-306

16. Guerra N, Tan YX, Joncker NT, Choy A, Gallardo F, Xiong N, Knoblaugh S, Cado D, Greenberg NM, Raulet DH. NKG2Ddeficient mice are defective in tumor surveillance in models of spontaneous malignancy. Immunity 2008; 28(4): 571-580

17. Coca S, Perez-Piqueras J, Martinez D, Colmenarejo A, Saez MA, Vallejo C, Martos JA, Moreno M. The prognostic significance of intratumoral natural killer cells in patients with colorectal carcinoma. Cancer 1997; 79(12): 2320-2328

18. Villegas FR, Coca S, Villarrubia VG, Jiménez R, Chillón MJ, Jareño J, Zuil M, Callol L. Prognostic significance of tumor infiltrating natural killer cells subset CD57 in patients with squamous cell lung cancer. Lung Cancer 2002; 35(1): 23-28

19. Taketomi A, Shimada M, Shirabe K, Kajiyama K, Gion T, Sugimachi K. Natural killer cell activity in patients with hepatocellular carcinoma: a new prognostic indicator after hepatectomy. Cancer 1998; 83(1): 58-63

20. Ishigami S, Natsugoe S, Tokuda K, Nakajo A, Che X, Iwashige H, Aridome K, Hokita S, Aikou T. Prognostic value of intratumoral natural killer cells in gastric carcinoma. Cancer 2000; 88(3): 577583

21. Takeuchi H, Maehara Y, Tokunaga E, Koga T, Kakeji Y, Sugimachi K. Prognostic significance of natural killer cell activity in patients with gastric carcinoma: a multivariate analysis. Am J Gastroenterol 2001; 96(2): 574-578

22. Larsen SK, Gao Y, Basse PH. NK cells in the tumor microenvironment. Crit Rev Oncog 2014; 19(1-2): 91-105

23. Shang B, Liu Y, Jiang SJ, Liu Y. Prognostic value of tumorinfiltrating $\mathrm{FoxP}^{+}$regulatory $\mathrm{T}$ cells in cancers: a systematic review and meta-analysis. Sci Rep 2015; 5(1): 15179

24. Shimizu J, Yamazaki S, Sakaguchi S. Induction of tumor immunity by removing $\mathrm{CD} 25^{+} \mathrm{CD} 4^{+} \mathrm{T}$ cells: a common basis between tumor immunity and autoimmunity. J Immunol 1999; 163(10): 52115218

25. Onizuka S, Tawara I, Shimizu J, Sakaguchi S, Fujita T, Nakayama E. Tumor rejection by in vivo administration of anti-CD25 (interleukin-2 receptor $\alpha$ ) monoclonal antibody. Cancer Res 1999; 59(13): 3128-3133

26. Yamaguchi $\mathrm{T}$, Sakaguchi S. Regulatory $\mathrm{T}$ cells in immune surveillance and treatment of cancer. Semin Cancer Biol 2006; 16(2): $115-123$

27. Campbell DJ, Koch MA. Treg cells: patrolling a dangerous neighborhood. Nat Med 2011; 17(8): 929-930

28. Quail DF, Joyce JA. Microenvironmental regulation of tumor progression and metastasis. Nat Med 2013; 19(11): 1423-1437

29. Chen Y, Zhang S, Wang Q, Zhang X. Tumor-recruited M2 macrophages promote gastric and breast cancer metastasis via M2 macrophage-secreted CHI3L1 protein. J Hematol Oncol 2017; 10 (1): 36

30. Yang L, Wang F, Wang L, Huang L, Wang J, Zhang B, Zhang Y. $\mathrm{CD}_{163^{+}}$tumor-associated macrophage is a prognostic biomarker and is associated with therapeutic effect on malignant pleural effusion of lung cancer patients. Oncotarget 2015; 6(12): 1059210603

31. Shigeoka M, Urakawa N, Nakamura T, Nishio M, Watajima T, Kuroda D, Komori T, Kakeji Y, Semba S, Yokozaki H. Tumor associated macrophage expressing CD204 is associated with tumor aggressiveness of esophageal squamous cell carcinoma. Cancer Sci 2013; 104(8): 1112-1119

32. Kim KJ, Wen XY, Yang HK, Kim WH, Kang GH. Prognostic implication of M2 macrophages are determined by the proportional balance of tumor associated macrophages and tumor infiltrating lymphocytes in microsatellite-unstable gastric carcinoma. PLoS One 2015; 10(12): e0144192

33. Grivennikov SI, Wang K, Mucida D, Stewart CA, Schnabl B, Jauch D, Taniguchi K, Yu GY, Osterreicher CH, Hung KE, Datz C, Feng Y, Fearon ER, Oukka M, Tessarollo L, Coppola V, Yarovinsky F, Cheroutre H, Eckmann L, Trinchieri G, Karin M. Adenoma-linked barrier defects and microbial products drive IL23/IL-17-mediated tumour growth. Nature 2012; 491(7423): 254 258

34. Greten FR, Karin M. The IKK/NF- $\mathrm{BB}$ activation pathway-a target for prevention and treatment of cancer. Cancer Lett 2004; 206(2): 193-199

35. Kong L, Zhou Y, Bu H, Lv T, Shi Y, Yang J. Deletion of interleukin-6 in monocytes/macrophages suppresses the initiation of hepatocellular carcinoma in mice. J Exp Clin Cancer Res 2016; 35(1): 131

36. Ueha S, Shand FH, Matsushima K. Myeloid cell population dynamics in healthy and tumor-bearing mice. Int Immunopharmacol 2011; 11(7): 783-788

37. Damuzzo V, Pinton L, Desantis G, Solito S, Marigo I, Bronte V, Mandruzzato S. Complexity and challenges in defining myeloidderived suppressor cells. Cytometry B Clin Cytom 2015; 88(2): 77-91

38. Hossain F, Al-Khami AA, Wyczechowska D, Hernandez C, Zheng L, Reiss K, Valle LD, Trillo-Tinoco J, Maj T, Zou W, Rodriguez PC, Ochoa AC. Inhibition of fatty acid oxidation modulates immunosuppressive functions of myeloid-derived suppressor cells 
and enhances cancer therapies. Cancer Immunol Res 2015; 3(11): 1236-1247

39. Xing F, Saidou J, Watabe K. Cancer associated fibroblasts (CAFs) in tumor microenvironment. Front Biosci (Landmark Ed) 2011; 15:166-179

40. Grum-Schwensen B, Klingelhofer J, Berg CH, El-Naaman C, Grigorian M, Lukanidin E, Ambartsumian N. Suppression of tumor development and metastasis formation in mice lacking the S100A4(mts1) gene. Cancer Res 2005; 65(9): 3772-3780

41. Goh PP, Sze DM, Roufogalis BD. Molecular and cellular regulators of cancer angiogenesis. Curr Cancer Drug Targets 2007; 7(8): 743-758

42. Orimo A, Gupta PB, Sgroi DC, Arenzana-Seisdedos F, Delaunay T, Naeem R, Carey VJ, Richardson AL, Weinberg RA. Stromal fibroblasts present in invasive human breast carcinomas promote tumor growth and angiogenesis through elevated SDF-1/CXCL12 secretion. Cell 2005; 121(3): 335-348

43. Li G, Satyamoorthy K, Meier F, Berking C, Bogenrieder T, Herlyn M. Function and regulation of melanoma-stromal fibroblast interactions: when seeds meet soil. Oncogene 2003; 22(20): $3162-3171$

44. Cunha GR, Hayward SW, Wang YZ. Role of stroma in carcinogenesis of the prostate. Differentiation 2002; 70(9-10): 473-485

45. Bindra RS, Glazer PM. Genetic instability and the tumor microenvironment: towards the concept of microenvironmentinduced mutagenesis. Mutat Res 2005; 569(1-2): 75-85

46. Yuan J, Glazer PM. Mutagenesis induced by the tumor microenvironment. Mutat Res 1998; 400(1-2): 439-446

47. Koukourakis MI, Giatromanolaki A, Harris AL, Sivridis E. Comparison of metabolic pathways between cancer cells and stromal cells in colorectal carcinomas: a metabolic survival role for tumor-associated stroma. Cancer Res 2006; 66(2): 632-637

48. Coussens LM, Werb Z. Inflammation and cancer. Nature 2002; 420 (6917): 860-867

49. Camps JL, Chang SM, Hsu TC, Freeman MR, Hong SJ, Zhau HE, von Eschenbach AC, Chung LW. Fibroblast-mediated acceleration of human epithelial tumor growth in vivo. Proc Natl Acad Sci USA 1990; 87(1): 75-79

50. Imai K. Matrix metalloproteinases and cancer cell invasion and metastasis. Tanpakushitsu Kakusan Koso 1997; 42(10 Suppl): 1694-1700 (in Japanese)

51. Akino T, Hida K, Hida Y, Tsuchiya K, Freedman D, Muraki C, Ohga N, Matsuda K, Akiyama K, Harabayashi T, Shinohara N, Nonomura K, Klagsbrun M, Shindoh M. Cytogenetic abnormalities of tumor-associated endothelial cells in human malignant tumors. Am J Pathol 2009; 175(6): 2657-2667

52. Amin DN, Hida K, Bielenberg DR, Klagsbrun M. Tumor endothelial cells express epidermal growth factor receptor (EGFR) but not ErbB3 and are responsive to EGF and to EGFR kinase inhibitors. Cancer Res 2006; 66(4): 2173-2180

53. Tsuchiya K, Hida K, Hida Y, Muraki C, Ohga N, Akino T, Kondo T, Miseki T, Nakagawa K, Shindoh M, Harabayashi T, Shinohara $\mathrm{N}$, Nonomura K, Kobayashi M. Adrenomedullin antagonist suppresses tumor formation in renal cell carcinoma through inhibitory effects on tumor endothelial cells and endothelial progenitor mobilization. Int J Oncol 2010; 36(6): 1379-1386
54. Matsuda K, Ohga N, Hida Y, Muraki C, Tsuchiya K, Kurosu T, Akino T, Shih SC, Totsuka Y, Klagsbrun M, Shindoh M, Hida K. Isolated tumor endothelial cells maintain specific character during long-term culture. Biochem Biophys Res Commun 2010; 394(4): 947-954

55. Maishi N, Ohba Y, Akiyama K, Ohga N, Hamada J, NagaoKitamoto H, Alam MT, Yamamoto K, Kawamoto T, Inoue N, Taketomi A, Shindoh M, Hida Y, Hida K. Tumour endothelial cells in high metastatic tumours promote metastasis via epigenetic dysregulation of biglycan. Sci Rep 2016; 6(1): 28039

56. Knutson KL, Disis ML. Tumor antigen-specific $\mathrm{T}$ helper cells in cancer immunity and immunotherapy. Cancer Immunol Immunother 2005; 54(8): 721-728

57. Yoon NK, Maresh EL, Shen D, Elshimali Y, Apple S, Horvath S, Mah V, Bose S, Chia D, Chang HR, Goodglick L. Higher levels of GATA3 predict better survival in women with breast cancer. Hum Pathol 2010; 41(12): 1794-1801

58. Erdag G, Schaefer JT, Smolkin ME, Deacon DH, Shea SM, Dengel LT, Patterson JW, Slingluff CL Jr. Immunotype and immunohistologic characteristics of tumor-infiltrating immune cells are associated with clinical outcome in metastatic melanoma. Cancer Res 2012; 72(5): 1070-1080

59. Nedergaard BS, Ladekarl M, Nyengaard JR, Nielsen K. A comparative study of the cellular immune response in patients with stage IB cervical squamous cell carcinoma. Low numbers of several immune cell subtypes are strongly associated with relapse of disease within 5 years. Gynecol Oncol 2008; 108(1): 106-111

60. Riemann D, Wenzel K, Schulz T, Hofmann S, Neef H, Lautenschläger C, Langner J. Phenotypic analysis of T lymphocytes isolated from non-small-cell lung cancer. Int Arch Allergy Immunol 1997; 114(1): 38-45

61. Al-Shibli KI, Donnem T, Al-Saad S, Persson M, Bremnes RM, Busund LT. Prognostic effect of epithelial and stromal lymphocyte infiltration in non-small cell lung cancer. Clin Cancer Res 2008; 14 (16): 5220-5227

62. Andreu P, Johansson M, Affara NI, Pucci F, Tan T, Junankar S, Korets L, Lam J, Tawfik D, DeNardo DG, Naldini L, de Visser KE, De Palma M, Coussens LM. FcR $\gamma$ activation regulates inflammation-associated squamous carcinogenesis. Cancer Cell 2010; 17(2): 121-134

63. de Visser KE, Korets LV, Coussens LM. De novo carcinogenesis promoted by chronic inflammation is B lymphocyte dependent. Cancer Cell 2005; 7(5): 411-423

64. Yuen GJ, Demissie E, Pillai S. B lymphocytes and cancer: a lovehate relationship. Trends Cancer 2016; 2(12): 747-757

65. Ammirante M, Luo JL, Grivennikov S, Nedospasov S, Karin M. Bcell-derived lymphotoxin promotes castration-resistant prostate cancer. Nature 2010; 464(7286): 302-305

66. Luo JL, Tan W, Ricono JM, Korchynskyi O, Zhang M, Gonias SL, Cheresh DA, Karin M. Nuclear cytokine-activated IKK $\alpha$ controls prostate cancer metastasis by repressing Maspin. Nature 2007; 446 (7136): 690-694

67. Woo JR, Liss MA, Muldong MT, Palazzi K, Strasner A, Ammirante M, Varki N, Shabaik A, Howell S, Kane CJ, Karin $\mathrm{M}$, Jamieson CA. Tumor infiltrating B-cells are increased in prostate cancer tissue. J Transl Med 2014; 12(1): 30

68. Ou Z, Wang Y, Liu L, Li L, Yeh S, Qi L, Chang C. Tumor 
microenvironment $\mathrm{B}$ cells increase bladder cancer metastasis via modulation of the IL-8/androgen receptor (AR)/MMPs signals. Oncotarget 2015; 6(28): 26065-26078

69. Rossi M, Young JW. Human dendritic cells: potent antigenpresenting cells at the crossroads of innate and adaptive immunity. J Immunol 2005; 175(3): 1373-1381

70. Tran Janco JM, Lamichhane P, Karyampudi L, Knutson KL. Tumor-infiltrating dendritic cells in cancer pathogenesis. J Immunol 2015; 194(7): 2985-2991

71. Ma Y, Shurin GV, Peiyuan Z, Shurin MR. Dendritic cells in the cancer microenvironment. J Cancer 2013; 4(1): 36-44

72. Jochems C, Schlom J. Tumor-infiltrating immune cells and prognosis: the potential link between conventional cancer therapy and immunity. Exp Biol Med (Maywood) 2011; 236(5): 567-579

73. Bekes EM, Schweighofer B, Kupriyanova TA, Zajac E, Ardi VC, Quigley JP, Deryugina EI. Tumor-recruited neutrophils and neutrophil TIMP-free MMP-9 regulate coordinately the levels of tumor angiogenesis and efficiency of malignant cell intravasation. Am J Pathol 2011; 179(3): 1455-1470

74. Eruslanov EB, Bhojnagarwala PS, Quatromoni JG, Stephen TL, Ranganathan A, Deshpande C, Akimova T, Vachani A, Litzky L, Hancock WW, Conejo-Garcia JR, Feldman M, Albelda SM, Singhal S. Tumor-associated neutrophils stimulate $\mathrm{T}$ cell responses in early-stage human lung cancer. J Clin Invest 2014; 124(12): $5466-5480$

75. Armulik A, Genové G, Betsholtz C. Pericytes: developmental, physiological, and pathological perspectives, problems, and promises. Dev Cell 2011; 21(2): 193-215

76. O'Keeffe MB, Devlin AH, Burns AJ, Gardiner TA, Logan ID, Hirst DG, McKeown SR. Investigation of pericytes, hypoxia, and vascularity in bladder tumors: association with clinical outcomes. Oncol Res 2008; 17(3): 93-101

77. Gee MS, Procopio WN, Makonnen S, Feldman MD, Yeilding NM, Lee WM. Tumor vessel development and maturation impose limits on the effectiveness of anti-vascular therapy. Am J Pathol 2003; 162(1): 183-193

78. Yonenaga Y, Mori A, Onodera H, Yasuda S, Oe H, Fujimoto A, Tachibana T, Imamura M. Absence of smooth muscle actinpositive pericyte coverage of tumor vessels correlates with hematogenous metastasis and prognosis of colorectal cancer patients. Oncology 2005; 69(2): 159-166

79. Sennino B, Falcón BL, McCauley D, Le T, McCauley T, Kurz JC, Haskell A, Epstein DM, McDonald DM. Sequential loss of tumor vessel pericytes and endothelial cells after inhibition of plateletderived growth factor B by selective aptamer AX102. Cancer Res 2007; 67(15): 7358-7367

80. Cooke VG, LeBleu VS, Keskin D, Khan Z, O'Connell JT, Teng Y, Duncan MB, Xie L, Maeda G, Vong S, Sugimoto H, Rocha RM, Damascena A, Brentani RR, Kalluri R. Pericyte depletion results in hypoxia-associated epithelial-to-mesenchymal transition and metastasis mediated by met signaling pathway. Cancer Cell 2012; 21(1): 66-81

81. Lu P, Weaver VM, Werb Z. The extracellular matrix: a dynamic niche in cancer progression. J Cell Biol 2012; 196(4): 395-406

82. Naba A, Clauser KR, Lamar JM, Carr SA, Hynes RO. Extracellular matrix signatures of human mammary carcinoma identify novel metastasis promoters. eLife 2014; 3e01308
83. Korpal M, Ell BJ, Buffa FM, Ibrahim T, Blanco MA, CeliàTerrassa T, Mercatali L, Khan Z, Goodarzi H, Hua Y, Wei Y, Hu G, Garcia BA, Ragoussis J, Amadori D, Harris AL, Kang Y. Direct targeting of Sec23a by miR-200s influences cancer cell secretome and promotes metastatic colonization. Nat Med 2011; 17(9): 11011108

84. Andrén-Sandberg A. Pancreatic cancer: chemotherapy and radiotherapy. N Am J Med Sci 2011; 3(1): 1-12

85. O'Reilly EA, Gubbins L, Sharma S, Tully R, Guang MH, WeinerGorzel K, McCaffrey J, Harrison M, Furlong F, Kell M, McCann A. The fate of chemoresistance in triple negative breast cancer (TNBC). BBA Clin 2015; 3: 257-275

86. Sun Y, Campisi J, Higano C, Beer TM, Porter P, Coleman I, True L, Nelson PS. Treatment-induced damage to the tumor microenvironment promotes prostate cancer therapy resistance through WNT16B. Nat Med 2012; 18(9): 1359-1368

87. DeNardo DG, Brennan DJ, Rexhepaj E, Ruffell B, Shiao SL, Madden SF, Gallagher WM, Wadhwani N, Keil SD, Junaid SA, Rugo HS, Hwang ES, Jirström K, West BL, Coussens LM. Leukocyte complexity predicts breast cancer survival and functionally regulates response to chemotherapy. Cancer Discov 2011; 1(1): 54-67

88. Ruffell B, Coussens LM. Macrophages and therapeutic resistance in cancer. Cancer Cell 2015; 27(4): 462-472

89. Takeuchi S, Baghdadi M, Tsuchikawa T, Wada H, Nakamura T, Abe H, Nakanishi S, Usui Y, Higuchi K, Takahashi M, Inoko K, Sato S, Takano H, Shichinohe T, Seino K, Hirano S. Chemotherapy-derived inflammatory responses accelerate the formation of immunosuppressive myeloid cells in the tissue microenvironment of human pancreatic cancer. Cancer Res 2015; 75(13): 2629-2640

90. Zheng H, Bae Y, Kasimir-Bauer S, Tang R, Chen J, Ren G, Yuan M, Esposito M, Li W, Wei Y, Shen M, Zhang L, Tupitsyn N, Pantel K, King C, Sun J, Moriguchi J, Jun HT, Coxon A, Lee B, Kang Y. Therapeutic antibody targeting tumor- and osteoblastic nichederived jagged1 sensitizes bone metastasis to chemotherapy. Cancer Cell 2017; 32(6): 731-747.e736

91. Paris F, Fuks Z, Kang A, Capodieci P, Juan G, Ehleiter D, Haimovitz-Friedman A, Cordon-Cardo C, Kolesnick R. Endothelial apoptosis as the primary lesion initiating intestinal radiation damage in mice. Science 2001; 293(5528): 293-297

92. Barker HE, Paget JT, Khan AA, Harrington KJ. The tumour microenvironment after radiotherapy: mechanisms of resistance and recurrence. Nat Rev Cancer 2015; 15(7): 409-425

93. Moeller BJ, Cao Y, Li CY, Dewhirst MW. Radiation activates HIF-1 to regulate vascular radiosensitivity in tumors: role of reoxygenation, free radicals, and stress granules. Cancer Cell 2004; 5(5): 429-441

94. Laoui D, Van Overmeire E, De Baetselier P, Van Ginderachter JA, Raes G. Functional relationship between tumor-associated macrophages and macrophage colony-stimulating factor as contributors to cancer progression. Front Immunol 2014; 5: 489

95. Zhou L, Zhang X, Li H, Niu C, Yu D, Yang G, Liang X, Wen X, Li $\mathrm{M}$, Cui J. Validating the pivotal role of the immune system in lowdose radiation-induced tumor inhibition in Lewis lung cancerbearing mice. Cancer Med 2018; 7(4): 1338-1348

96. Smalley KS, Xiao M, Villanueva J, Nguyen TK, Flaherty KT, Letrero R, Van Belle P, Elder DE, Wang Y, Nathanson KL, Herlyn 
M. CRAF inhibition induces apoptosis in melanoma cells with non-V600E BRAF mutations. Oncogene 2009; 28(1): 85-94

97. Wilhelm SM, Adnane L, Newell P, Villanueva A, Llovet JM, Lynch M. Preclinical overview of sorafenib, a multikinase inhibitor that targets both Raf and VEGF and PDGF receptor tyrosine kinase signaling. Mol Cancer Ther 2008; 7(10): 3129-3140

98. Sprinzl MF, Reisinger F, Puschnik A, Ringelhan M, Ackermann K, Hartmann D, Schiemann M, Weinmann A, Galle PR, Schuchmann M, Friess H, Otto G, Heikenwalder M, Protzer U. Sorafenib perpetuates cellular anticancer effector functions by modulating the crosstalk between macrophages and natural killer cells. Hepatology 2013; 57(6): 2358-2368

99. Ozao-Choy J, Ma G, Kao J, Wang GX, Meseck M, Sung M, Schwartz M, Divino CM, Pan PY, Chen SH. The novel role of tyrosine kinase inhibitor in the reversal of immune suppression and modulation of tumor microenvironment for immune-based cancer therapies. Cancer Res 2009; 69(6): 2514-2522

100. Suh KJ, Sung JH, Kim JW, Han SH, Lee HS, Min A, Kang MH, Kim JE, Kim JW, Kim SH, Lee JO, Kim YJ, Lee KW, Kim JH, Bang SM, Im SA, Lee JS. EGFR or HER2 inhibition modulates the tumor microenvironment by suppression of PD-L1 and cytokines release. Oncotarget 2017; 8(38): 63901-63910

101. Huang J, Wang L, Cong Z, Amoozgar Z, Kiner E, Xing D, Orsulic S, Matulonis U, Goldberg MS. The PARP1 inhibitor BMN 673 exhibits immunoregulatory effects in a Brca1 $(-/-)$ murine model of ovarian cancer. Biochem Biophys Res Commun 2015; 463(4): 551-556

102. Evans T, Matulonis U. PARP inhibitors in ovarian cancer: evidence, experience and clinical potential. Ther Adv Med Oncol 2017; 9(4): 253-267

103. Fujishita T, Kojima Y, Kajino-Sakamoto R, Taketo MM, Aoki M. Tumor microenvironment confers mTOR inhibitor resistance in invasive intestinal adenocarcinoma. Oncogene 2017; 36(46): 6480-6489

104. Jiao S, Xia W, Yamaguchi H, Wei Y, Chen MK, Hsu JM, Hsu JL, Yu WH, Du Y, Lee HH, Li CW, Chou CK, Lim SO, Chang SS, Litton J, Arun B, Hortobagyi GN, Hung MC. PARP inhibitor upregulates PD-L1 expression and enhances cancer-associated immunosuppression. Clin Cancer Res 2017; 23(14): 3711-3720

105. Pander J, Heusinkveld M, van der Straaten T, Jordanova ES, BaakPablo R, Gelderblom H, Morreau H, van der Burg SH, Guchelaar HJ, van Hall T. Activation of tumor-promoting type 2 macrophages by EGFR-targeting antibody cetuximab. Clin Cancer Res 2011; 17(17): 5668-5673

106. Recouvreux S, Sampayo R, Bessone MI, Simian M. Microenvironment and endocrine resistance in breast cancer: friend or foe? World J Clin Oncol 2015; 6(6): 207-211

107. Smith JA, Das A, Butler JT, Ray SK, Banik NL. Estrogen or estrogen receptor agonist inhibits lipopolysaccharide induced microglial activation and death. Neurochem Res 2011; 36(9): $1587-1593$

108. Keeton EK, Brown M. Cell cycle progression stimulated by tamoxifen-bound estrogen receptor- $\alpha$ and promoter-specific effects in breast cancer cells deficient in N-CoR and SMRT. Mol Endocrinol 2005; 19(6): 1543-1554

109. Escamilla J, Schokrpur S, Liu C, Priceman SJ, Moughon D, Jiang Z, Pouliot F, Magyar C, Sung JL, Xu J, Deng G, West BL, Bollag
G, Fradet Y, Lacombe L, Jung ME, Huang J, Wu L. CSF1 receptor targeting in prostate cancer reverses macrophage-mediated resistance to androgen blockade therapy. Cancer Res 2015; 75(6): 950962

110. Qian BZ, Pollard JW. Macrophage diversity enhances tumor progression and metastasis. Cell 2010; 141(1): 39-51

111. De Palma M, Lewis CE. Macrophage regulation of tumor responses to anticancer therapies. Cancer Cell 2013; 23(3): 277286

112. Liu Y, Fan L, Wang Y, Li P, Zhu J, Wang L, Zhang W, Zhang Y, Huang G. Tumor-associated macrophages promote tumor cell proliferation in nasopharyngeal NK/T-cell lymphoma. Int J Clin Exp Pathol 2014; 7(9): 5429-5435

113. Yang Y, Bai Y, He Y, Zhao Y, Chen J, Ma L, Pan Y, Hinten M, Zhang J, Karnes RJ, Kohli M, Westendorf JJ, Li B, Zhu R, Huang $\mathrm{H}, \mathrm{Xu} \mathrm{W}$. PTEN loss promotes intratumoral androgen synthesis and tumor microenvironment remodeling via aberrant activation of RUNX2 in castration-resistant prostate cancer. Clin Cancer Res 2018; 24(4): 834-846

114. Wang D, DuBois RN. Immunosuppression associated with chronic inflammation in the tumor microenvironment. Carcinogenesis 2015; 36(10): 1085-1093

115. Topalian SL, Drake CG, Pardoll DM. Immune checkpoint blockade: a common denominator approach to cancer therapy. Cancer Cell 2015; 27(4): 450-461

116. Buchbinder EI, Desai A. CTLA-4 and PD-1 pathways: similarities, differences, and implications of their inhibition. Am J Clin Oncol 2016; 39(1): 98-106

117. Chambers CA, Kuhns MS, Egen JG, Allison JP. CTLA-4mediated inhibition in regulation of $\mathrm{T}$ cell responses: mechanisms and manipulation in tumor immunotherapy. Annu Rev Immunol 2001; 19(1): 565-594

118. Collins AV, Brodie DW, Gilbert RJ, Iaboni A, Manso-Sancho R, Walse B, Stuart DI, van der Merwe PA, Davis SJ. The interaction properties of costimulatory molecules revisited. Immunity 2002; 17(2): 201-210

119. Parry RV, Chemnitz JM, Frauwirth KA, Lanfranco AR, Braunstein I, Kobayashi SV, Linsley PS, Thompson CB, Riley JL. CTLA-4 and PD-1 receptors inhibit T-cell activation by distinct mechanisms. Mol Cell Biol 2005; 25(21): 9543-9553

120. Keir ME, Butte MJ, Freeman GJ, Sharpe AH. PD-1 and its ligands in tolerance and immunity. Annu Rev Immunol 2008; 26(1): 677704

121. He J, Hu Y, Hu M, Li B. Development of PD-1/PD-L1 pathway in tumor immune microenvironment and treatment for non-small cell lung cancer. Sci Rep 2015; 5(1): 13110

122. Leach DR, Krummel MF, Allison JP. Enhancement of antitumor immunity by CTLA-4 blockade. Science 1996; 271(5256): 17341736

123. Postow MA, Callahan MK, Wolchok JD. Immune checkpoint blockade in cancer therapy. J Clin Oncol 2015; 33(17): 1974-1982

124. Maker AV, Attia P, Rosenberg SA. Analysis of the cellular mechanism of antitumor responses and autoimmunity in patients treated with CTLA-4 blockade. J Immunol 2005; 175(11): 77467754

125. Quezada SA, Peggs KS, Curran MA, Allison JP. CTLA4 blockade and GM-CSF combination immunotherapy alters the intratumor 
balance of effector and regulatory T cells. J Clin Invest 2006; 116 (7): 1935-1945

126. Takahashi T, Tagami T, Yamazaki S, Uede T, Shimizu J, Sakaguchi N, Mak TW, Sakaguchi S. Immunologic self-tolerance maintained by $\mathrm{CD} 25(+) \mathrm{CD} 4(+)$ regulatory $\mathrm{T}$ cells constitutively expressing cytotoxic $\mathrm{T}$ lymphocyte-associated antigen 4. J Exp Med 2000; 192(2): 303-310

127. Hodi FS, Mihm MC, Soiffer RJ, Haluska FG, Butler M, Seiden MV, Davis T, Henry-Spires R, MacRae S, Willman A, Padera R, Jaklitsch MT, Shankar S, Chen TC, Korman A, Allison JP, Dranoff G. Biologic activity of cytotoxic T lymphocyte-associated antigen 4 antibody blockade in previously vaccinated metastatic melanoma and ovarian carcinoma patients. Proc Natl Acad Sci USA 2003; 100(8): 4712-4717

128. Alsaab HO, Sau S, Alzhrani R, Tatiparti K, Bhise K, Kashaw SK, Iyer AK. PD-1 and PD-L1 checkpoint signaling inhibition for cancer immunotherapy: mechanism, combinations, and clinical outcome. Front Pharmacol 2017; 8: 561

129. Riaz N, Havel JJ, Makarov V, Desrichard A, Urba WJ, Sims JS, Hodi FS, Martin-Algarra S, Mandal R, Sharfman WH, Bhatia S, Hwu WJ, Gajewski TF, Slingluff CL Jr, Chowell D, Kendall SMChang H, Shah R, Kuo F, Morris LGT, Sidhom JW, Schneck JP, Horak CE, Weinhold N, Chan TA. Tumor and microenvironment evolution during immunotherapy with nivolumab. Cell 2017; 171(4): 934-949.e915

130. Lichty BD, Breitbach CJ, Stojdl DF, Bell JC. Going viral with cancer immunotherapy. Nat Rev Cancer 2014; 14(8): 559-567

131. Mastrangelo MJ, Maguire HC Jr, Eisenlohr LC, Laughlin CE, Monken CE, McCue PA, Kovatich AJ, Lattime EC. Intratumoral recombinant GM-CSF-encoding virus as gene therapy in patients with cutaneous melanoma. Cancer Gene Ther 1999; 6(5): 409-422

132. de Vries CR, Kaufman HL, Lattime EC. Oncolytic viruses: focusing on the tumor microenvironment. Cancer Gene Ther 2015; 22(4): 169-171

133. Park BH, Hwang T, Liu TC, Sze DY, Kim JS, Kwon HC, Oh SY, Han SY, Yoon JH, Hong SH, Moon A, Speth K, Park C, Ahn YJ, Daneshmand M, Rhee BG, Pinedo HM, Bell JC, Kirn DH. Use of a targeted oncolytic poxvirus, JX-594, in patients with refractory primary or metastatic liver cancer: a phase I trial. Lancet Oncol 2008; 9(6): 533-542

134. Kaufman HL, DeRaffele G, Divito J, Hörig H, Lee D, Panicali D, Voulo M. A phase I trial of intralesional $\mathrm{rV}$-Tricom vaccine in the treatment of malignant melanoma. Hum Gene Ther 2001; 12(11): $1459-1480$

135. Kaufman HL, Kim DW, DeRaffele G, Mitcham J, Coffin RS, KimSchulze S. Local and distant immunity induced by intralesional vaccination with an oncolytic herpes virus encoding GM-CSF in patients with stage IIIc and IV melanoma. Ann Surg Oncol 2010; 17(3): 718-730

136. Kudo-Saito C, Schlom J, Hodge JW. Intratumoral vaccination and diversified subcutaneous/ intratumoral vaccination with recombinant poxviruses encoding a tumor antigen and multiple costimulatory molecules. Clin Cancer Res 2004; 10(3): 1090-1099

137. de Vries CR, Monken CE, Lattime EC. The addition of recombinant vaccinia HER2/neu to oncolytic vaccinia-GMCSF given into the tumor microenvironment overcomes MDSCmediated immune escape and systemic anergy. Cancer Gene
Ther 2015; 22(3): 154-162

138. Gulley JL, Heery CR, Madan RA, Walter BA, Merino MJ, Dahut WL, Tsang KY, Schlom J, Pinto PA. Phase I study of intraprostatic vaccine administration in men with locally recurrent or progressive prostate cancer. Cancer Immunol Immunother 2013; 62(9): 15211531

139. Madan RA, Heery CR, Gulley JL. Poxviral-based vaccine elicits immunologic responses in prostate cancer patients. Oncoimmunology 2014; 3e28611

140. Anassi E, Ndefo UA. Sipuleucel-T (provenge) injection: the first immunotherapy agent (vaccine) for hormone-refractory prostate cancer. P T 2011; 36(4): 197-202

141. Ojha T, Pathak V, Shi Y, Hennink WE, Moonen CTW, Storm G, Kiessling F, Lammers T. Pharmacological and physical vessel modulation strategies to improve EPR-mediated drug targeting to tumors. Adv Drug Deliv Rev 2017; 119: 44-60

142. Gao W, Li S, Liu Z, Sun Y, Cao W, Tong L, Cui G, Tang B. Targeting and destroying tumor vasculature with a near-infrared laser-activated "nanobomb" for efficient tumor ablation. Biomaterials 2017; 139: 1-11

143. Kunjachan S, Detappe A, Kumar R, Ireland T, Cameron L, Biancur DE, Motto-Ros V, Sancey L, Sridhar S, Makrigiorgos GM, Berbeco RI. Nanoparticle mediated tumor vascular disruption: a novel strategy in radiation therapy. Nano Lett 2015; 15(11): 74887496

144. Miao L, Wang Y, Lin CM, Xiong Y, Chen N, Zhang L, Kim WY, Huang L. Nanoparticle modulation of the tumor microenvironment enhances therapeutic efficacy of cisplatin. J Control Release 2015; 217: $27-41$

145. Hu K, Miao L, Goodwin TJ, Li J, Liu Q, Huang L. Quercetin remodels the tumor microenvironment to improve the permeation, retention, and antitumor effects of nanoparticles. ACS Nano 2017; 11(5): 4916-4925

146. Miao L, Liu Q, Lin CM, Luo C, Wang Y, Liu L, Yin W, Hu S, Kim WY, Huang L. Targeting tumor-associated fibroblasts for therapeutic delivery in desmoplastic tumors. Cancer Res 2017; 77(3): 719-731

147. Lee S, Han H, Koo H, Na JH, Yoon HY, Lee KE, Lee H, Kim H, Kwon IC, Kim K. Extracellular matrix remodeling in vivo for enhancing tumor-targeting efficiency of nanoparticle drug carriers using the pulsed high intensity focused ultrasound. J Control Release 2017; 263: 68-78

148. Zhou H, Fan Z, Deng J, Lemons PK, Arhontoulis DC, Bowne WB, Cheng H. Hyaluronidase embedded in nanocarrier PEG shell for enhanced tumor penetration and highly efficient antitumor efficacy. Nano Lett 2016; 16(5): 3268-3277

149. Gong H, Chao Y, Xiang J, Han X, Song G, Feng L, Liu J, Yang G, Chen Q, Liu Z. Hyaluronidase to enhance nanoparticle-based photodynamic tumor therapy. Nano Lett 2016; 16(4): 2512-2521

150. Shay G, Lynch CC, Fingleton B. Moving targets: emerging roles for MMPs in cancer progression and metastasis. Matrix Biol 2015; 44-46: 200-206

151. Hu XX, He PP, Qi GB, Gao YJ, Lin YX, Yang C, Yang PP, Hao H, Wang L, Wang H. Transformable nanomaterials as an artificial extracellular matrix for inhibiting tumor invasion and metastasis. ACS Nano 2017; 11(4): 4086-4096 